\title{
DISCONTINUIDADES Y LIMITACIONES DE LOS ÚLTIMOS PLANES TURÍSTICOS DE ESPAÑA EN RELACIÓN A LA SOSTENIBILIDAD AMBIENTAL DEL TURISMO DE SOL Y PLAYA*
}

\author{
Raquel Santos-Lacueva** \\ Salvador Anton Clave**** \\ Òscar Saladie ${ }^{* * * * * *}$ \\ Universitat Rovira i Virgili
}

\section{RESUMEN}

El turismo de sol y playa es una actividad estratégica para la economía española que depende altamente de los recursos naturales que la posibilitan. Para garantizar su competitividad y su sostenibilidad futura es imprescindible la incorporación de medidas ambientales en la política turística. El análisis crítico argumentativo de los tres últimos planes turísticos aprobados por el gobierno de España permite observar el alcance y las limitaciones de la incorporación de tales medidas. Los poderes públicos reconocen la persistencia de los problemas ambientales pero esto no siempre se ha plasmado en los planes.

Palabras clave: Geografía del turismo, planes turísticos, análisis de políticas públicas, medioambiente, sostenibilidad, sol y playa.

Recibido: 10 de marzo de 2016

Devuelto para su revisión: 5 de septiembre de 2016

Aceptado: 30 de octubre de 2016

* Este artículo se ha realizado en el marco de las actividades del Grupo de Investigación en Análisis Territorial y Estudios Turísticos de la URV y ha contado con el apoyo del Ministerio de Economía y Competitividad del Gobierno de España (MOVETUR CSO2014-51785-R) y el Programa Serra Húnter de la Generalitat de Cataluña.

** Departamento de Geografía. Universitat Rovira i Virgili. c/ Joanot Martorell, 15. Vila-Seca. TARRAGONA (España).E-mail: raquel.santos@urv.cat, salvador.anton@urv.cat,oscar.saladie@urv.cat

*** Cátedra Dow/URV de Desarrollo Sostenible. Universitat Rovira i Virgili. E-mail: oscar.saladie@urv.cat 


\title{
Discontinuities and limitations of the most recent Spanish tourism plans related to the environmental sustainability of sun and sand tourism
}

\begin{abstract}
Coastal tourism is a strategic activity for the Spanish economy, highly dependent on natural resources. Tourism policies must incorporate environmental measures to ensure tourism competitiveness and future sustainability. The scope and limitation of this incorporation is analyzed by means of an argumentative critical analysis of the last three tourism plans approved by the Spanish administration. Public authorities recognize the persistence of environmental problems but this has not always been translated into the plans.
\end{abstract}

Keywords: Tourism geography, tourism planning, Public Policy Analysis, environment, sustainability, sun sand and sea

\section{INTRODUCCIÓN}

El turismo es una actividad estratégica para la economía española, no sólo por sus efectos compensatorios sobre el desequilibrio de la balanza de pagos, sino también por su carácter transversal y su capacidad motriz sobre otros sectores económicos (Cuadrado Roura y López Morales, 2011). Según reconocen los poderes públicos es una apuesta prioritaria para el crecimiento económico y la generación de empleo (Secretaría General de Turismo, 2007; Secretaría de Estado de Turismo y Turespaña, 2012).

Algunos datos constatan la magnitud del sector. En 2015, el turismo fue la actividad económica que más creció y que más empleo generó, con un aumento del PIB de 3,7\%, medio punto por encima de la media española (Exceltur, 2016). Los afiliados a la seguridad social en las actividades características del turismo superaron los 2 millones (Turespaña, 2015). Según los datos provisionales de la Encuesta de Ocupación de Alojamientos Turísticos para 2015, España cuenta con 14.553 establecimientos hoteleros abiertos, sin incluir otro tipo de oferta como apartamentos o campings, que suman 1.436 .135 plazas (INE, 2015). A nivel mundial, en 2014 España fue el tercer país en número de visitantes, con más de 65 millones, y el segundo en ingresos por turismo internacional, superando los 65 millones de dólares (OMT, 2015). Estos datos se deben mayormente a su producto principal: el turismo de sol y playa, el motor central de desarrollo del sector (Secretaría General de Turismo, 2007, p. 23). Así, la costa concentra el 69,5\% de plazas de alojamiento (Eurostat, 2014) y son las Comunidades Autónomas del litoral mediterráneo, junto con los dos archipiélagos, los territorios que más turistas internacionales reciben: Cataluña $(25,9 \%)$, Canarias $(17,7 \%)$, Islas Baleares $(17,5 \%)$, Andalucía $(13,1 \%)$ y Comunidad Valenciana $(9,6 \%)$ (Turespaña, 2014).

Esta situación actual se explica por el éxito inicial de los primeros destinos de sol y playa y la réplica de su patrón de desarrollo a lo largo de buena parte de la costa mediterránea e insular a partir los años 60 del pasado siglo. Este patrón, con ritmos rápidos 
de crecimiento desde sus inicios, ha propiciado la concentración espacial y temporal de la demanda. Más allá de su situación actual y del posicionamiento internacional privilegiado en los mercados de los principales destinos, es de interés apuntar que ya a partir de la década de los 80 del siglo XX se observaron y documentaron, sin embargo, signos de madurez e incluso de declive en la dinámica de crecimiento iniciada durante las dos décadas anteriores (Beas Secall, 2009; Borrell Merlin, 2005). Tanto es así que desde diversos ámbitos incluso se puso en duda la sostenibilidad futura de algunos de los destinos más representativos (Secretaría General de Turismo, 1990; Anton Clavé, 1992; Knowles and Curtis, 1999). Fue con la intención de revertir esta situación, que ya desde aquel momento se alentaron procesos de diversificación y recualificación que, si bien han tenido resultados variables, en términos generales han permitido reposicionar en los mercados, tal como puede observarse en la actualidad, algunos de los principales destinos de sol y playa españoles y, en algunos casos, incluso mejorar sus condiciones ambientales (Anton Clavé, 2004; Vera Rebollo y Rodríguez, 2012).

Beneficiándose de las condiciones climáticas, el producto de sol y playa se fundamenta en el aprovechamiento de los recursos naturales de las zonas costeras, bien sea transformando el territorio y los usos del suelo para la dotación de infraestructuras y alojamiento, o bien sea acondicionando el litoral para el disfrute de los bañistas. Su consumo se realiza in situ y, por tanto, no debería desvincularse de la planificación medioambiental ni de la ordenación territorial y su desarrollo tampoco debería sobrepasar la capacidad de carga de los destinos (Vera Rebollo y Baños Castiñeira, 2004). Desde esta perspectiva, el medioambiente no es sólo un medio de producción, sino que genera un espacio de consumo y es un condicionante para la satisfacción de una demanda cada vez más preocupada por cuestiones medioambientales (Leslie, 2012; Santos Pavón y Fernández Tabales, 2010). En consecuencia, parece lógico que "la preservación medioambiental también debiera entenderse como una fuente de ingresos turísticos de manera que al adoptar cualquier decisión de crecimiento debiera ser necesario comparar los costes y beneficios que conlleva la transformación del medio" (León, 2004, p. 296).

Teniendo en cuenta estas consideraciones, resulta obvio que para garantizar la sostenibilidad futura del turismo español de sol y playa como actividad estratégica, es necesario afrontar algunos de los problemas que acarrea desde sus inicios su relación con el medio ambiente. Son los ligados, principalmente, a la concentración espacial y temporal, a la sobreocupación del litoral y a la masificación y abaratamiento de la oferta, que afectan principalmente la calidad de los recursos que fundamentan la actividad turística, desde el agua del mar y las playas, al paisaje. Problemas, por otra parte, directamente vinculados a los resultados económicos y empresariales de la actividad. Además, en el contexto globalizado actual, el turismo de sol y playa debe enfrentarse a nuevos retos cada vez más complejos, difusos y que generan mayor incertidumbre, como el cambio climático. Todo ello, unido a la intersectorialidad y las características propias de la actividad turística, hace inevitable la intervención pública, cuya eficiencia y pertinencia serán claves para determinar el éxito y la sostenibilidad futura de los destinos. Así pues, resulta imprescindible analizar y ampliar los instrumentos de acción pública que favorezcan la sostenibilidad futura del sector. 
En este contexto, este trabajo propone un análisis crítico de los tres últimos planes turísticos aprobados de España -el Plan de Turismo Español Horizonte 2020, el Plan de Turismo Español 0812 y el Plan Nacional e Integral de Turismo 2012-2015 (en adelante, Plan 2020, Plan 0812, Plan 1215, respectivamente)- a partir del estudio específico del uso que en ellos se hace del criterio de sostenibilidad medioambiental para el turismo de sol y playa. En particular, tiene por objeto: (1) poner de manifiesto la importancia del análisis argumentativo de la cuestión medioambiental en el marco de las políticas turísticas, en tanto que, como se observa a través de estos planes, este mismo asunto puede concebirse, explicarse y priorizarse de forma muy diferente, lo cual tiene implicaciones directas sobre la sostenibilidad futura de la actividad; y (2) identificar algunas de las deficiencias tradicionales en la planificación turística española ligadas a los problemas de sostenibilidad medioambiental y a la insuficiente coordinación entre la política turística y la medioambiental.

Se parte de la consideración de que la intervención pública en la actividad turística es necesaria para paliar los efectos negativos que genera el turismo y que el mercado no es capaz de corregir o compensar. La transversalidad propia del sector turístico implicaría la coordinación y planificación conjunta entre diferentes áreas políticas (Elliott, 1997; Hall, 1994; Monfort Mir, 2000). De hecho, en las políticas dirigidas explícitamente a intervenir en la actividad turística, confluyen muchas otras que pese a enmarcarse en otros sectores, provocan impactos directos en el turismo (Comisión Europea, 2010; Page y Connell, 2006). Estas particularidades convierten a la política turística en "un objeto de análisis amorfo y sin límites" (Velasco González, 2004, p. 69) que, además, se produce en un contexto globalizado, incierto y dinámico que dificulta la investigación de las políticas turísticas. Es por este motivo que este tipo de políticas no pueden tratarse como una rama más de la política económica o industrial sino que necesitan incorporar variables múltiples, interactivas y, en algunos casos, incluso difusas.

El artículo se plantea abordar este cometido a partir del enfoque del Análisis de la Políticas Públicas. De esta manera se pretenden superar algunos de los vacíos todavía persistentes en la investigación sobre las políticas turísticas (Jenkins et al., 2014; Dredge y Jamal, 2015). En este ámbito han predominado tradicionalmente trabajos centrados en estudios de casos, líneas de tiempo, ejemplos de buenas prácticas (Jenkins et al., 2014) o guías de propuestas (Dredge y Jamal, 2015). Sin embargo, el Análisis de Políticas Públicas, como conjunto de herramientas de las ciencias sociales que permite estructurar la investigación sobre políticas que atañen a cuestiones complejas y transversales, como es el turismo, ha permitido incorporar nuevas preocupaciones y refinar los planteamientos de análisis. Así, desde los estudios positivistas iniciales, basados en la comprobación empírica de inputs y outputs, hasta las perspectivas que tratan de responder cuestiones como el peso de las ideas en la acción pública, la influencia de las politics en la policy o cómo los argumentos y discursos políticos determinan los cambios de rumbo de las políticas públicas (Harguindéguy, 2015), el Análisis de Políticas Públicas ha permitido abordar cuestiones como la que nos ocupa en este artículo, de manera sistemática y ordenada.

El trabajo se estructura en tres apartados, además de la presente introducción y un apartado final de conclusiones. Primero, se contextualiza el problema de la sostenibilidad medioambiental en la planificación turística española; segundo, se exponen los aspectos 
metodológicos y se justifica la utilidad del análisis crítico de contenidos de los planes turísticos; y tercero, se analizan los tres últimos planes turísticos españoles y su vinculación medioambiental.

\section{ANTECEDENTES EN LA PLANIFICACIÓN TURÍSTICA ESPAÑOLA Y LA SOSTENIBILIDAD AMBIENTAL DEL TURISMO DE SOL Y PLAYA}

Está ampliamente aceptada la definición de desarrollo sostenible como aquel que satisface las necesidades del presente sin comprometer las generaciones futuras (ONU, 1987), abarcando tres dimensiones interdependientes: ambiental, económica y social. Deben combinarse de forma equilibrada la protección y conservación de los recursos naturales, el desarrollo económico equitativo y la contribución al bienestar social (Ministerio de la Presidencia, 2007; Saladié y Oliveras, 2010). Además, algunos autores consideran una cuarta dimensión: la institucional. Esta se relaciona con el concepto de gobernanza y contempla que los poderes públicos tienen capacidad para influir, liderar y legitimar el cambio hacia la sostenibilidad en lo relativo al turismo (Provan y Kenis, 2007; Farinós, 2008; Torres-Delgado, 2010; López Sánchez y Pulido Fernández, 2013; Pulido Fernández y López Sánchez, 2013). Por otro lado, se entiende por desarrollo turístico sostenible al "proceso de cambio cualitativo producto de la voluntad política que, con la participación imprescindible de la población local, adapta el marco institucional y legal, así como los instrumentos de planificación y gestión, a un desarrollo turístico basado en un equilibrio entre la preservación del patrimonio natural y cultural, la viabilidad económica del turismo y la equidad social del desarrollo" (Ivars, 2001, p. 11).

El análisis que se realiza en este artículo se centra en el eje ambiental de la sostenibilidad y, por lo tanto, en uno de los principales problemas del turismo de sol y playa como es el mantenimiento de la calidad ambiental de los recursos naturales del cual depende. Efectivamente, está ampliamente aceptado que uno de los grandes atractivos del producto de sol y playa en España es la combinación de unas agradables condiciones climáticas en la costa con el disfrute de sus recursos naturales, como la playa y el medio marino. El clima es un factor de localización de la actividad turística y se considera un recurso en sí mismo. Además es motivo de atracción de demanda, ya que las condiciones climáticas son un aspecto fundamental a la hora de escoger un destino de vacaciones (de Freitas, Scott y McBoyle, 2008; Gómez Martín, 2004; Scott y Mcboyle, 2001). De hecho, se da una elevada concentración temporal durante el verano (estacionalidad), que también está influenciada por factores como los periodos vacacionales institucionales (especialmente los escolares) o las tendencias y modas sociales (Amelung, Nicholls y Viner, 2007). Es así cómo y por qué durante la temporada alta se pueden saturar los servicios y las infraestructuras del litoral, perjudicando a los turistas pero también a la población local, y además generando efectos negativos sobre el medioambiente.

La oferta de sol y playa conlleva la concentración espacial de la actividad y, en particular, la artificialización y la pérdida de valor ecológico y paisajístico (difícilmente recuperables) del litoral. Si bien Fernández Tabales et al. (2014) identifican algunas excepciones de municipios que han rechazado abiertamente el crecimiento turístico asociado al mercado inmobiliario, llegando incluso a desclasificar suelo urbanizable para apostar 
por la calidad, sostenibilidad y competitividad del destino, esta no ha sido la dinámica general. Por el contrario, la presión sobre el litoral se ha visto agravada por la urbanización desmedida ligada al boom inmobiliario y a la expansión del turismo residencial (Borrell Merlin, 2007; Jiménez Herrero, 2007; Pérez, 2012,) pero también al propio crecimiento urbano, industrial, logístico y portuario asociado a las ciudades localizadas en el litoral.

Está, además, el problema del crecimiento localizado de determinadas tipologías de oferta, su impacto sobre el medio ambiente y el paisaje y, en consecuencia, el abaratamiento de precios en los destinos donde se concentran tales tipologías. Efectivamente, el rápido desarrollo turístico español se ha fundamentado tradicionalmente en el aumento de la oferta y en el ajuste continuado de precios a la baja con el objetivo de atraer un número de turistas cada vez mayor. El auge de las compañías aéreas de bajo coste ha intensificado esta dinámica (Quintiliani, 2009; Vera Rebollo y Ivars, 2009) y todo ello ha tenido como resultado en algunos casos la pérdida de la capacidad de atracción del destino (Buhalis, 2000) y su deterioro urbano, físico y ambiental. Como se verá más adelante, tanto el Plan 2020 (Secretaría General de Turismo, 2007, p. 20) como el Plan 1215 (Secretaría de Estado de Turismo y Turespaña, 2012, p. 30) admiten explícitamente esta problemática.

Asimismo, el crecimiento del turismo de sol y playa en España se ha caracterizado, desde la perspectiva de sus efectos sobre el medio ambiente, por los déficits de planificación. De acuerdo con el estudio de Velasco González (2008), la deficiencia en los instrumentos de planificación ya aparece mencionada en el Plan Nacional de Turismo de 1953 y asuntos como los impactos negativos del turismo sobre el medio ambiente o la necesidad de protección de las costas y de gestión del paisaje ya se recogen en el II Plan de Desarrollo Económico de 1968-1971. En esta misma línea, Velasco González (2008) explica que no es hasta el II Plan Futures (1996-1999) cuando aparecen las primeras referencias concretas a la sostenibilidad ambiental. Sin duda influyó el contexto de reconocimiento del valor del medio ambiente en el progreso económico en general y la aparición de medidas y orientaciones a nivel europeo en este sentido (Anton Clavé, 1992). Velasco González (2010) reconoce, en cualquier caso, que, aunque puntuales e insuficientes, han existido acciones que demuestran voluntad de coordinación entre la administración turística y medioambiental. Por ejemplo, las medidas aprobadas en 2009 por ambos Ministerios, como la creación del Centro para la Sostenibilidad y las Tecnologías Ambientales del Turismo o la adopción de medidas para el fomento del desarrollo turístico sostenible del medio rural.

Finalmente, más recientemente se ha observado que la sostenibilidad ambiental del modelo turístico no sólo depende de la apropiada conservación medioambiental, sino también de la capacidad de los agentes públicos y privados para mitigar los impactos negativos (Eijgelaar y Peeters, 2014) derivados de dinámicas de cambio global (Pulido Fernández, 2011). En este último aspecto destacan: (1) los cambios en el modelo energético y de transportes, asociados al peak oil, que afectan a la movilidad de la demanda y a la accesibilidad del destino (Prideaux, 2013); (2) la aparición de nuevos mercados emergentes, que igualan o tienen capacidad para emular aspectos propios del modelo español -clima, playa y precio-, y que además gozan de mayor exotismo y de una riqueza ambiental menos explotada; y (3) el cambio climático, cuyas consecuencias principales -aumento de temperaturas y del nivel del mar- pueden provocar, entre 
otras cosas, el desplazamiento de la demanda hacia zonas con temperaturas más suaves y meses menos calurosos, además de afectaciones a la línea de costa (Becken y Hay, 2012; OMT, 2007; Scott, 2014).

En esta línea hace ya más de una década, Pulido Fernández (2004) abogaba por una reorientación medioambiental de la política turística, de manera que los aspectos ambientales tuvieran un trato preferente para garantizar la sostenibilidad de los destinos. Ante este conjunto de situaciones, López Sánchez y Pulido Fernández (2013) sostienen que el tratamiento dado a la sostenibilidad en la planificación turística española ha sido parcial y erróneo y justifican muchos de los problemas del sector turístico por la ausencia de una planificación estratégica a largo plazo guiada por el criterio de sostenibilidad. Pulido Fernández y Pulido Fernández (2015) defienden, además, la necesidad de superar la sostenibilidad como recurso retórico y propagandístico para que se traduzca en acciones reales. Existen deficiencias entre la escala política, que trata de orientar la sostenibilidad de la actividad turística, y su traducción en la práctica (Farsari, et al., 2011; Bramwell y Lane, 2014; Maxim, 2016), que a menudo se da en forma de acciones aisladas motivadas por la reducción de costes o la mejora de imagen (Buckley, 2012). Para superarlo, es imprescindible la implicación de los poderes públicos, además de los agentes privados, la sociedad local y los propios turistas. También es necesaria una mayor coordinación entre el propio sector turístico, el ámbito académico y los gobiernos, que entran en conflicto en cuestiones de regulación y protección (Buckley, 2012).

Los diferentes grados de implicación también se deberían producir entre los distintos niveles administrativos. Torres-Delgado y López Palomeque (2012) analizan la contribución de las iniciativas institucionales relacionadas con la política turística en la difusión y aplicación del concepto de turismo sostenible, e identifican un mayor peso de los agentes europeos e internacionales, así como una mayor acepción del término de sostenibilidad en su vertiente medioambiental.

Se observa, en cualquier caso, la necesidad de ahondar en el análisis de la problemática medioambiental asociada al turismo costero desde la perspectiva de las políticas que se han implementado al respecto y desde la perspectiva de su estudio a partir del enfoque del Análisis de las Políticas Públicas. Todo ello, también, en aras de colaborar en la sostenibilidad futura de esta actividad.

\section{METODOLOGÍA: APROXIMACIÓN AL ANÁLISIS CRÍTICO ARGUMENTA- TIVO DE POLÍTICAS PÚBLICAS}

El ámbito turístico está cargado de controversias, problemas y conflictos de intereses sin resolver, que se escapan a las explicaciones que puedan darse desde los marcos teóricos tradicionales y usando métodos convencionales. Cómo se incorporan las ideas a las políticas turísticas, cómo se justifican las decisiones que se toman, qué narrativas se utilizan para explicar el contexto actual o cómo se utiliza el saber experto para argumentar la toma de decisiones, son algunas de las cuestiones que deben afrontarse para comprender las dinámicas turísticas actuales, y para dar respuesta a los nuevos retos y gestionar los problemas persistentes que no logran resolverse. Uno de ellos es el que nos ocupa: la sostenibilidad medioambiental de los destinos de sol y playa. 
El enfoque de Análisis de Políticas Públicas permite abordar este problema desde una perspectiva nueva que parte del convencimiento de que el mejor conocimiento de las políticas turísticas facilitará una mejor gestión del fenómeno turístico. El Análisis de Políticas Públicas se entiende aquí como un conjunto de herramientas de las ciencias sociales que permite articular la investigación sobre la acción pública pudiendo adoptar diferentes enfoques teóricos, cumplir diversos fines aplicados, centrarse en variados objetos de estudio y utilizar distintas técnicas (p.e Fisher et al., 2007; Parsons, 1995; Subirats, 1989). Su propia evolución ha permitido pulir sus planteamientos teóricos y metodológicos y ha trasladado el interés positivista inicial centrado en el análisis de inputs y outputs, como un paso final de evaluación de resultados tras la implementación de políticas, hacia otras cuestiones más complejas como, por ejemplo, los cambios de escala en las políticas públicas en un contexto globalizado, la gestión de los bienes comunes, la influencia de las ideas y los paradigmas o el uso del saber experto para justificar la toma de decisiones (Harguindéguy, 2015).

Concretamente, este artículo afronta el estudio de las políticas públicas orientadas al planteamiento de las cuestiones ambientales asociadas a la sostenibilidad de las dinámicas turísticas de los destinos de sol y playa desde la perspectiva del análisis de marcos argumentativos y de discursos (Fisher y Forester, 1993; Fisher y Gottweis, 2012). Se trata de un enfoque crítico, flexible e interpretativo que se considera de gran utilidad para analizar la complejidad de los procesos de acción pública ligados al turismo y que ya se ha aplicado a otras cuestiones medioambientales (Hajer, 1993). Este enfoque considera las cualidades argumentativas y el debate político como elementos clave para explicar los procesos de formulación de políticas públicas y los cambios políticos. Se definen las políticas como un "constructo de marcos interpretativos compartidos en los discursos y debates políticos"; el proceso de formulación se concibe como un "trascurso interactivo de aprendizaje e intercambio de argumentos y significados"; y el contexto institucional se observa a través de "coaliciones y comunidades políticas que comparten sistemas de creencias, valores y paradigmas interpretativos" (Enserink, et. al 2013 p.25).

El concepto de política pública alude a un nivel estratégico y decisor y engloba todos los instrumentos operativos y de intervención a través de los que se articula. Puede entenderse como "un conjunto de decisiones tomadas y de acciones emprendidas por una serie de actores, tanto públicos como privados, orientadas a la solución de un problema claramente delimitado" (Subirats et al., 2008, p. 11). Por su parte, los planes, que son el objeto de atención del análisis que se realiza en este artículo, son considerados los "elementos instrumentales estratégicos que articulan un conjunto de acciones, programas, proyectos y servicios que se consideran prioritarios para alcanzar los objetivos de una política. Son, junto a las leyes, los instrumentos y medidas que despliegan, en un primer nivel, los idearios de gobierno" (AEVAL, 2010, p. 50). Los planes son el instrumento programático, que articulan un conjunto de ideas, valores e intenciones sobre cierta materia, en este caso turismo (Velasco González, 2011). A diferencia de los programas, se orientan hacia la totalidad del sector turístico, en vez de a un apartado concreto. Constituyen el reflejo de la voluntad política, poniendo de manifiesto cómo percibe la Administración la actividad turística: qué alcanza el grado de problema y, por tanto, cuán necesaria resulta su intervención para resolverlo; cuál es su magnitud como problema; y cómo se pretende solucionarlo. Además, para el éxito de un plan debe garantizarse un amplio consenso público-privado entre los actores interesados. 
El método consiste en llevar a cabo un análisis crítico e interpretativo discursivo de los contenidos de los documentos públicos relevantes. El examen sistemático de la información permite no sólo constatar las decisiones tomadas, sino también interpretar e inferir detalles relevantes sobre los problemas a observar. En este caso, primero se lleva a cabo un análisis de contenidos, que es una técnica cualitativa apropiada para trabajar con documentos extensos y que permite la clasificación y la cuantificación de determinados aspectos del texto. Para más detalles sobre esta metodología pueden consultarse Guthrie (2010), Kohlbacher (2006), Mayring (2000) o Weber (1990). A continuación, se propone la comparación de planes turísticos con la finalidad de poder emitir conclusiones acerca de la mejora o empeoramiento de la política turística española respecto a la cuestión medioambiental. Para ello se sugieren una serie de indicadores básicos que, además de permitir la comparación de las cuestiones fundamentales de los planes en relación al principio de sostenibilidad ambiental, facilitan la síntesis del análisis crítico e interpretativo previo de contenidos.

En concreto, se plantea destacar los siguientes puntos: 1) cómo se incluye o no el principio de sostenibilidad ambiental en la visión del plan; 2) si el periodo de planificación permite la inserción de este principio estratégico que necesita largos plazos para su articulación; 3) si el principio aparece o no en los ejes estratégicos principales; 4) si los criterios de priorización (si los hay) condicionan el cumplimiento de dicho principio estratégico; 5) qué se propone en relación a la coordinación política entre turismo y medioambiente; y 6) la frecuencia de palabras clave. A los efectos del análisis a realizar, se proponen seis indicadores que se corresponden a los seis puntos mencionados: 1) Meta o visión estratégica; 2) Periodo de planificación (años); 3 ) Ejes o líneas estratégicas principales; 4) Criterios de priorización de medidas propuestas; 5) Coordinación explícita entre turismo y medioambiente; 6) Frecuencia de palabras clave de acuerdo al tema que se trata (sostenible, sostenibles o sostenibilidad; y medioambiente, medioambiental, ambiente o ambiental). Los tres primeros responden a cuestiones esenciales de planificación estratégica; el cuarto y el quinto surgen como aspectos clave que sintetizan parte del análisis interpretativo de contenidos; y el sexto es un indicador habitual de las técnicas de análisis de contenidos para cuantificar el peso de determinados temas en el texto, complementando así el análisis cualitativo. Además, esta propuesta de indicadores tiene voluntad de aplicabilidad futura para facilitar la síntesis y comparación de otros documentos de planificación turística.

En este trabajo se analizan los tres últimos planes de turismo en España (Plan 2020, Plan 0812, Plan 1215) y se comparan el Plan 2020 y el Plan 1215 tratando como un único documento los planes 2020 y 0812 en tanto que forman parte de la misma lógica de planificación y cuya unión se equipara a la extensión del Plan 1215 (138 y 123 páginas, respectivamente).

\section{EL MEDIO AMBIENTE EN LOS TRES ÚLTIMOS PLANES TURÍSTICOS ESPAÑOLES}

\subsection{El Plan del Turismo Español Horizonte 2020 (Plan 2020)}

El Plan 2020 fue impulsado desde el Ministerio de Industria, Turismo y Comercio y se aprobó en noviembre de 2007 bajo el Gobierno socialista de José Luis Rodríguez 
Zapatero. El Plan 2020 se describe a sí mismo como un hito para la política turística y se autoconsidera un proceso innovador, por su visión estratégica a largo plazo y por el amplio proceso participativo que le respalda. La extensión del documento es de 88 páginas y tiene una cobertura temporal de 14 años. Tiene como meta "lograr en el horizonte 2020 que el sistema turístico español sea el más competitivo y sostenible, aportando el máximo bienestar social" (Secretaría General de Turismo, 2007, p. 13 y 45).

Tabla 1

ESTRUCTURA DEL PLAN 2020

\begin{tabular}{|c|c|c|}
\hline \multirow{26}{*}{ Plan 2020} & \multicolumn{2}{|l|}{ Introducción } \\
\hline & \multirow{5}{*}{ 1. Tendencias 2020} & Económicas \\
\hline & & Políticas \\
\hline & & Sociodemográficas \\
\hline & & Medioambientales \\
\hline & & Tecnológicas \\
\hline & \multirow{3}{*}{$\begin{array}{l}\text { 2. Diagnóstico y retos del sistema } \\
\text { turístico }\end{array}$} & 2.1 Diagnóstico por áreas prioritarias \\
\hline & & 2.2 Retos del Sistema Turístico Español \\
\hline & & 2.3 Retos de los productos turísticos españoles \\
\hline & \multicolumn{2}{|c|}{ 3. Conclusiones del diagnóstico y las tendencias } \\
\hline & \multirow{5}{*}{ 4. Participación y debate } & 4.1 Entorno de demanda \\
\hline & & 4.2 Entorno experto \\
\hline & & 4.3 Entorno empresarial y profesional \\
\hline & & 4.4 Entorno público \\
\hline & & 4.5 Entorno social \\
\hline & \multirow{6}{*}{ 5. Meta y orientación estratégica } & Principio Planificación \\
\hline & & Principio Equilibrio y recualificación \\
\hline & & Principio Diferenciación \\
\hline & & Principio Especialización \\
\hline & & Principio Simplificación \\
\hline & & Principio Compromiso \\
\hline & \multirow{5}{*}{$\begin{array}{l}\text { 6. Objetivos y estrategias del } \\
\text { turismo español en el horizonte } \\
2020\end{array}$} & Eje Nueva economía turística \\
\hline & & Eje Valor al cliente \\
\hline & & Eje Sostenibilidad del modelo \\
\hline & & Eje Entorno competitivo \\
\hline & & Eje Liderazgo compartido \\
\hline \multirow{3}{*}{ Plan 0812} & \multicolumn{2}{|l|}{ Introducción } \\
\hline & \multicolumn{2}{|l|}{ 7. Principios operativos } \\
\hline & \multicolumn{2}{|l|}{ 8. Programas } \\
\hline
\end{tabular}

Fuente: elaboración propia a partir del Plan 2020.

Cuadernos de Turismo, 40, (2017), 599-626 
El Plan 2020, como se recoge en la Tabla 1, se divide en seis apartados, además de una introducción. Una primera fase de este Plan se implementa a través del Plan del Turismo Español 08-12 (Plan 0812) que, como se observa, se incluye anexo al mismo documento y forma parte de la misma lógica argumental.

El contenido del texto permite afirmar que los poderes públicos reconocen la importancia del medioambiente para el turismo de España. Considerando en conjunto el Plan 2020 y el Plan 0812, en tanto que forman parte de un mismo documento y la extensión de ambos es similar a la del Plan 1215, lo que facilita la comparación, las palabras clave sostenible, sostenibles o sostenibilidad aparecen 108 veces; y medioambiente, ambiente, medioambiental y ambiental, se observan en 76 ocasiones. El concepto de sostenibilidad aparece repetidas veces, destacando en la meta del plan y en uno de los cinco ejes en los que se estructura. Siguiendo el orden de la Tabla 1, ya el primer apartado del Plan 2020 dedica una sección a las dinámicas medioambientales. Se describe la previsión de escenarios durante el periodo de cobertura del plan y, en cuestión de sostenibilidad medioambiental, se acepta la importancia del medioambiente para el turismo. Además, contempla la sostenibilidad medioambiental tanto desde el punto de vista de la demanda como de la propia competitividad de los agentes de la actividad: "la adopción de medidas en materia de medio ambiente por parte del sector turístico vendrá determinada no sólo porque esté en la agenda política, sino sobre todo porque de una buena conservación del medio y de un uso eficiente de los recursos dependerá -en definitiva- el futuro del sector, tanto desde el punto de vista de la competitividad como por una mayor sensibilidad de la demanda que exigirá cada vez más la sostenibilidad económica, medioambiental y social en sus opciones de compra" (Secretaría General de Turismo, 2007, p. 17).

En la siguiente sección del Plan, se lleva a cabo un diagnóstico de fortalezas y debilidades dividido en cuatro áreas, así como una identificación de retos para el sistema turístico en su conjunto y para productos específicos. El contenido se resume en la Tabla 2, donde aparecen sombreados los apartados que tienen que ver con el objeto de este artículo y que se describen a continuación.

Entre las fortalezas, destacan el clima -apartado destinos-, o la amplia oferta de playas con buena calidad de aguas -apartado oferta y productos-. Como debilidades de los destinos, se reconoce la madurez del turismo de sol y playa, así como los problemas de estandarización, masificación, litoralización, estacionalización y deterioro ambiental y paisajístico. Esta misma sección enumera una serie de retos que deben afrontarse en aras de una mayor competitividad, tanto para el sistema turístico español en general, como para una serie de productos turísticos en concreto, entre ellos el turismo de sol y playa. Para este producto concreto se considera que se debe "mejorar en aquellos aspectos que los turistas peor valoran del turismo sol y playa español: calidad paisajística y medioambiental, masificación y pérdida de identidad" (Secretaría General de Turismo, 2007, p. 31). También pueden relacionarse con los impactos ambientales el "mejorar las metodologías y herramientas de soporte a la planificación turística y su traslación a la ordenación territorial y urbanística" (Secretaría General de Turismo, 2007, p. 26) y el "romper la fuerte estacionalidad de los flujos turísticos"(Secretaría General de Turismo, 2007, p. 28). 


\section{Tabla 2 \\ ESTRUCTURA DEL APARTADO DIAGNÓSTICO Y RETOS DEL SISTEMA TURÍSTICO DEL PLAN 2020}

\begin{tabular}{|c|c|c|c|}
\hline \multirow{20}{*}{$\begin{array}{l}\text { 2. Diagnóstico } \\
\text { y retos del } \\
\text { sistema } \\
\text { turístico }\end{array}$} & \multirow{8}{*}{$\begin{array}{l}2.1 \\
\text { Diagnóstico } \\
\text { por áreas } \\
\text { prioritarias }\end{array}$} & \multirow{2}{*}{ Competitividad } & Fortalezas \\
\hline & & & Debilidades \\
\hline & & \multirow{2}{*}{ Destinos } & Fortalezas \\
\hline & & & Debilidades \\
\hline & & \multirow{2}{*}{ Oferta y productos } & Fortalezas \\
\hline & & & Debilidades \\
\hline & & \multirow{2}{*}{$\begin{array}{l}\text { Modelos de gestión y recursos } \\
\text { humanos }\end{array}$} & Fortalezas \\
\hline & & & Debilidades \\
\hline & & \multicolumn{2}{|c|}{ 1. Mejorar metodologías y herramientas de planificación } \\
\hline & & \multicolumn{2}{|c|}{ 2. Adaptarse a nuevas tendencias de destinos emergentes } \\
\hline & & \multicolumn{2}{|c|}{ 3. Adecuar gestión y comercialización a nuevas necesidades } \\
\hline & $\begin{array}{l}2.2 \text { Retos } \\
\text { del Sistema }\end{array}$ & \multicolumn{2}{|c|}{$\begin{array}{l}\text { 4. Mejorar presencia en mercados lejanos y con mayor poder } \\
\text { adquisitivo }\end{array}$} \\
\hline & Español & \multicolumn{2}{|l|}{ 5. Fidelizar la demanda } \\
\hline & & \multicolumn{2}{|l|}{ 6. Romper la estacionalidad } \\
\hline & & \multicolumn{2}{|c|}{ 7. Mejorar la gestión de RRHH: temporalidad y cualificación } \\
\hline & & \multicolumn{2}{|l|}{ 8. Aumentar la competitividad } \\
\hline & & \multicolumn{2}{|l|}{ Turismo de sol y playa } \\
\hline & los productos & \multicolumn{2}{|l|}{ Turismo cultural y de ciudad } \\
\hline & turísticos & \multicolumn{2}{|c|}{ Turismo de reuniones, congresos e incentivos } \\
\hline & espanoles & \multicolumn{2}{|l|}{ Turismo deportivo } \\
\hline
\end{tabular}

Fuente: elaboración propia a partir del Plan 2020.

La tercera sección del Plan 2020 -Conclusiones del diagnóstico y las tendenciasseñala "la necesidad de mejorar el equilibrio entre la actividad turística y su entorno. Las prioridades de actuación en sostenibilidad deben contemplar la comprensión de los impactos que genera el sector en el entorno, además de los generados por el entorno sobre el sector. Es necesario revisar el ritmo y modelo de crecimiento de la actividad turística (...) para incorporar sus requerimientos de competitividad-sostenibilidad" (Secretaría General de Turismo, 2007, p. 37). Se evidencia pues, que los poderes públicos son conscientes de la interdependencia existente entre medioambiente y turismo, así como de la necesidad de paliar los impactos negativos generados, incorporando criterios de sostenibilidad y responsabilidad ambiental para garantizar la competitividad del sector turístico. 
La sección Meta y orientación estratégica queda justificada en los procesos de diagnóstico y participación explicados en la sección previa de Participación y Debate. Hace referencia a los seis principios en los que se basará esta nueva orientación: planificación, equilibrio y recualificación, diferenciación, especialización, simplificación y compromiso. La importancia que se le da en este plan a la sostenibilidad como principio transversal se intuye ya en el enunciado de su meta expuesto anteriormente. De este modo, se quiere que "el turismo siga siendo un pilar para el crecimiento y desarrollo de la economía y la sociedad española en el horizonte 2020, optimizando los beneficios socioeconómicos, garantizando la calidad del entorno natural y cultural e induciendo un menor impacto ambiental." (Secretaría General de Turismo, 2007, p. 45).

La última sección del Plan 2020, recoge los Objetivos y estrategias del turismo español en el horizonte 2020. Se estructuran entorno a cinco ejes, como esquematiza la Figura 1. Para cada eje se especifican los nuevos requerimientos, las carencias de adaptación, los objetivos y las estrategias.

\section{Figura 1 \\ EJES CLAVE DE ACTUACIÓN DEL PLAN 2020}

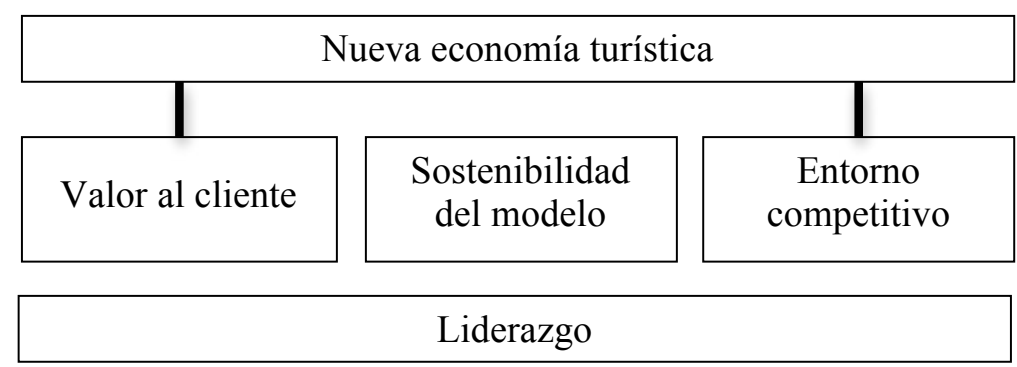

Fuente: Plan 2020.

Lo más destacable en relación al tema de estudio, es que uno de los cinco ejes de actuación se dedica a la sostenibilidad. Su objetivo es: "mejorar la sostenibilidad del modelo turístico español, optimizando los beneficios por unidad de capacidad de carga sostenible y de inversión, garantizando la calidad del entorno natural y cultural de cada lugar, la integración y bienestar social y el reequilibrio socio territorial" (Secretaría General de Turismo, 2007, p. 70). La Tabla 3 sintetiza los contenidos del eje, resaltando los aspectos vinculados directamente con el medioambiente. Aunque el eje trata de la sostenibilidad en general, sin especial referencia a la cuestión medioambiental, se observa que existe un alto grado de vinculación con el medio ambiente.

Finalmente, sobre la necesidad de mejorar la coordinación de la política turística y la medioambiental, en el Plan 2020 puede leerse que "la Comisión Interministerial de Turismo ha puesto de manifiesto la necesidad de una mayor participación del turismo en el conjunto de políticas sectoriales" (Secretaría General de Turismo, 2007, p. 43). Concretamente, se identifican cinco áreas prioritarias de coordinación, entre ellas el medioambiente. 


\section{Tabla 3}

\section{ESTRUCTURA DEL EJE SOSTENIBILIDAD DEL MODELO DEL PLAN 2020}

\begin{tabular}{|c|c|c|}
\hline & & $\begin{array}{l}\text { Demanda de la sociedad de una mayor contribución económico-social } \\
\text { por unidad de carga requerida de la actividad turística }\end{array}$ \\
\hline & & $\begin{array}{l}\text { Mayor valoración de los atributos medioambientales de los destinos y } \\
\text { mayor exigencia sobre la gestión ambiental turística }\end{array}$ \\
\hline & $\begin{array}{l}\text { Nuevos } \\
\text { requerimientos } \\
\text { del entorno }\end{array}$ & $\begin{array}{l}\text { Demanda de la sociedad receptora de una mayor contribución de la } \\
\text { actividad turística a la preservación de la cultura, valores y entornos } \\
\text { naturales propios }\end{array}$ \\
\hline & & $\begin{array}{l}\text { Exigencia de la demanda de una mayor diferenciación y } \\
\text { especialización de los destinos turísticos }\end{array}$ \\
\hline & & $\begin{array}{l}\text { Necesidad de paliar el efecto de concentración y saturación } \\
\text { provocado por la actividad turística }\end{array}$ \\
\hline & & $\begin{array}{l}\text { Desequilibrio socioterritorial de los beneficios del turismo por la } \\
\text { concentración de la actividad, principalmente en los destinos del } \\
\text { litoral }\end{array}$ \\
\hline Eje & & $\begin{array}{l}\text { Sobreexplotación de determinados recursos y destinos turísticos que } \\
\text { amenaza con superar su capacidad de carga }\end{array}$ \\
\hline $\begin{array}{l}\text { Sostenibilidad } \\
\text { del modelo }\end{array}$ & $\begin{array}{l}\text { Carencias de } \\
\text { adaptación al }\end{array}$ & $\begin{array}{l}\text { Utilización intensiva del territorio y de los recursos naturales que } \\
\text { afectan al valor y la imagen del producto }\end{array}$ \\
\hline & nuevo entorno & $\begin{array}{l}\text { Declive de algunos destinos importantes de la costa derivado de la } \\
\text { falta de inversión en su mantenimiento }\end{array}$ \\
\hline & & $\begin{array}{l}\text { Dificultad para asegurar las infraestructuras y suministros de servicios } \\
\text { básicos con repercusión en la calidad de hábitats }\end{array}$ \\
\hline & & $\begin{array}{l}\text { Inexistencia de un análisis del coste de oportunidad de los desarrollos } \\
\text { urbanísticos que comprometen nuevos crecimientos futuros }\end{array}$ \\
\hline & & Compromiso con la sostenibilidad y la responsabilidad social \\
\hline & Ohiotivo & Reforzar los procesos estratégicos de los destinos turísticos \\
\hline & Oojenvo & Gestionando la madurez de los destinos turísticos \\
\hline & & Desestacionalización y reequilibrio socio-territorial \\
\hline & & Turismo, medio ambiente y sociedad \\
\hline & Fstrateoizs & Planificación y gestión de los destinos turísticos \\
\hline & Latrate gias & Recualificación de destinos turísticos maduros \\
\hline & & Desestacionalización y reequilibrio territorial \\
\hline
\end{tabular}

Fuente: elaboración propia a partir del Plan 2020.

\subsection{El Plan del Turismo Español 0812 (Plan 0812)}

El Plan 0812 surge del mismo proceso que el Plan 2020. Tiene una extensión de 50 páginas y una cobertura temporal de cinco años. Su meta, aunque no se menciona, es compartida con el Plan 2020. Son programas y medidas que dan operatividad a la estrategia del Plan 2020 para los primeros 5 años. Como muestra la Tabla 4, se divide en tres secciones: una introducción, la descripción de los cuatro principios operativos y el grueso del documento con los programas para cada eje de actuación, de acuerdo a los ejes y estrategias 
del Plan 2020. Cada programa fija un objetivo general, unos objetivos operativos y las líneas de acción para ejecutarlos. Puesto que lo que interesa en este análisis es lo relativo a la sostenibilidad ambiental y el Plan 0812 comparte lógica estructural con el Plan 2020, se detalla a continuación el eje Sostenibilidad del modelo, resumido en la Tabla 5. Hay que destacar las acciones del programa Turismo, medioambiente y sociedad. Sus objetivos son: identificar y evaluar los impactos generados por el turismo, establecer indicadores efectivos de sostenibilidad, sensibilizando e involucrando a todos los agentes, para mejorar la sostenibilidad de los destinos y "reducir los impactos medioambientales y sobre la sociedad generados por el sector turístico" (Secretaría General de Turismo, 2007, p. 119). Todas las líneas de acción de este programa se orientan al logro de estos fines, subrayando como ejemplos, la voluntad de crear un observatorio de turismo y sostenibilidad (TU2); participar desde la administración turística en la estrategia nacional del cambio climático (TU5); o establecer una red internacional de cooperación de turismo y sostenibilidad.

Tabla 4

ESTRUCTURA DEL PLAN 0812

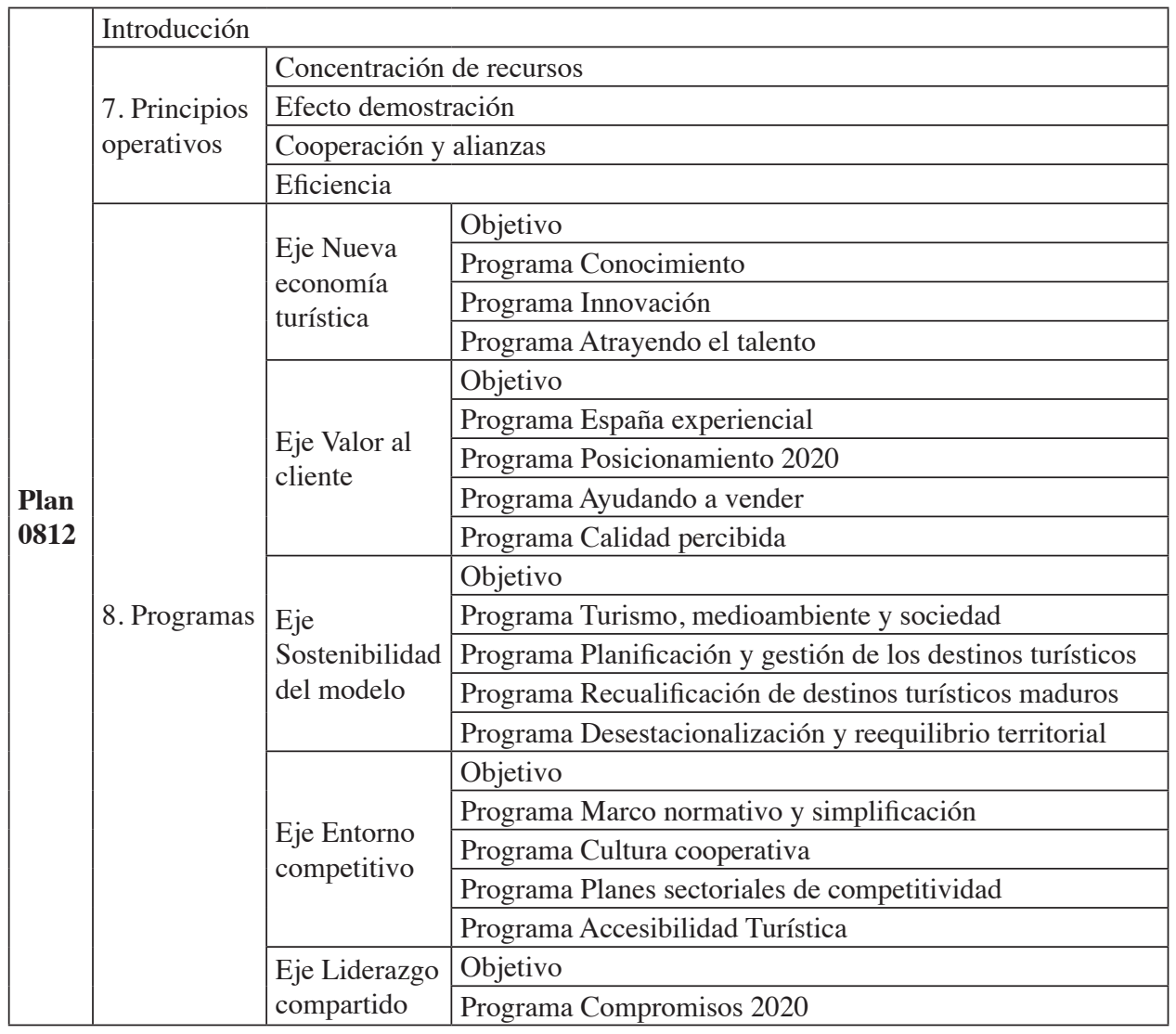

Fuente: elaboración propia a partir del Plan 0812. 
El programa Planificación y gestión de destinos turísticos hace hincapié en la relación entre calidad, competitividad y sostenibilidad. A grandes rasgos, se pretende establecer una visión estratégica del sector teniendo en cuenta, entre otros aspectos, el desarrollo territorial o la calidad del entorno. Destaca la línea PA1, que habla de evaluar el binomio competitividad-sostenibilidad, dada "una demanda cada vez más exigente, una sociedad más sensibilizada y un medioambiente más frágil" (Secretaría General de Turismo, 2007, p. 122). El programa Recualificación de destinos turísticos maduros, también busca mejorar la relación competitividad-sostenibilidad, para obtener mayor beneficio económico, social y ambiental. No obstante, el último programa -Desestacionalización y reequilibrio socioterritorial-, no hace ninguna referencia a las graves implicaciones medioambientales relacionadas con la estacionalidad y la concentración espacial del turismo.

\section{Tabla 5}

ESTRUCTURA DEL EJE SOSTENIBILIDAD DEL MODELO DEL PLAN 0812

\begin{tabular}{|c|c|c|}
\hline \multirow{18}{*}{$\begin{array}{l}\text { Eje } \\
\text { Sostenibilidad } \\
\text { del modelo }\end{array}$} & Objetivo & Líneas de acción \\
\hline & \multirow{6}{*}{$\begin{array}{l}\text { Programa Turismo, } \\
\text { medioambiente y } \\
\text { sociedad }\end{array}$} & $\begin{array}{l}\text { TU1 Conocimiento e identificación de bases para la } \\
\text { sostenibilidad turística }\end{array}$ \\
\hline & & TU2 Observatorio del turismo y la sostenibilidad \\
\hline & & TU3 Sensibilización y formación en sostenibilidad \\
\hline & & $\begin{array}{l}\text { TU4 Proyectos demostrativos en red de turismo y medio } \\
\text { ambiente }\end{array}$ \\
\hline & & TU5 Códigos y compromisos por la sostenibilidad \\
\hline & & $\begin{array}{l}\text { TU6 Modelo de reconocimiento de la responsabilidad } \\
\text { social }\end{array}$ \\
\hline & \multirow{4}{*}{$\begin{array}{l}\text { Programa } \\
\text { Planificación y } \\
\text { gestión de los } \\
\text { destinos turísticos }\end{array}$} & $\begin{array}{l}\text { PA1 Herramientas de evaluación de la competitividad- } \\
\text { sostenibilidad }\end{array}$ \\
\hline & & $\begin{array}{l}\text { PA2 Metodologías para la planificación y gestión de } \\
\text { destinos turísticos }\end{array}$ \\
\hline & & PA3 Impulso a la planificación estratégica \\
\hline & & $\begin{array}{l}\text { PA4 Gestión de destinos: refuerzo de capacidades y } \\
\text { conocimiento }\end{array}$ \\
\hline & \multirow{3}{*}{$\begin{array}{l}\text { Programa } \\
\text { Recualificación de } \\
\text { destinos turísticos } \\
\text { maduros }\end{array}$} & $\begin{array}{l}\text { RE1 Proyectos extraordinarios de recualificación de } \\
\text { destinos maduros }\end{array}$ \\
\hline & & $\begin{array}{l}\text { RE2 Rehabilitación de equipamientos y entornos urbanos } \\
\text { y naturales }\end{array}$ \\
\hline & & RE3 Modernización de la oferta turística \\
\hline & \multirow{4}{*}{$\begin{array}{l}\text { Programa } \\
\text { Desestacionalización } \\
\text { y reequilibrio } \\
\text { territorial }\end{array}$} & $\begin{array}{l}\text { DE1 Identificación de oportunidades: mapa de recursos } \\
\text { para la desestacionalización }\end{array}$ \\
\hline & & $\begin{array}{l}\text { DE2 Planes en destinos sobre productos, itinerarios y } \\
\text { rutas temáticas }\end{array}$ \\
\hline & & DE3 Planes de desestacionalización \\
\hline & & $\begin{array}{l}\text { DE4 Modelo de cooperación en red entre destinos } \\
\text { participantes }\end{array}$ \\
\hline
\end{tabular}

Fuente: elaboración propia a partir del Plan 0812. 
Pese a que el eje Sostenibilidad del modelo es el más relevante para el tema de este artículo, también deben mencionarse otras alusiones que aparecen en otros ejes del Plan 0812. Por ejemplo, el programa Innovación -Eje Nueva economía- tiene por objeto, entre otros, "promover el diseño e implementación de nuevos modelos, sistemas y herramientas de planificación y gestión de los destinos turísticos, sus infraestructuras y recursos básicos, dirigidos a obtener mejoras sociales, culturales y medioambientales, anticipando y mitigando los impactos de la actividad turística en el entorno" (Secretaría General de Turismo, 2007, p. 99). Este programa también agrupa medidas de gestión ambiental o de eficiencia energética.

Respecto a la coordinación entre las administraciones turística y medioambiental, destaca la línea de acción Grupos de trabajo de la Comisión Interministerial, del programa Marco normativo y simplificación y del eje Entorno competitivo. Aquí se propone adecuar la normativa estatal a la realidad turística, y expresamente la "medioambiental referida, entre otras cosas, a la gestión de residuos, gestión del agua y gestión energética de hoteles y otros establecimientos turísticos, que favorezca de manera eficiente la innovación tecnológica y la sostenibilidad en las demandas de los clientes" (Secretaría General de Turismo, 2007, p. 130). Dentro del mismo eje, el programa Cultura cooperativa habla de reforzar las funciones de la Conferencia Interministerial de Turismo. Entre sus líneas de acción, se incluyen los Planes anuales de acción interministerial a favor del turismo, que deben incluir las necesidades del sector relacionadas con políticas de otros ministerios y las acciones de colaboración interdepartamental, haciendo especial mención a seis y siendo uno de ellos la sostenibilidad medioambiental y el turismo. Este mismo también contiene el programa Planes sectoriales de competitividad, que deberán elaborarse analizando una serie de puntos, siendo uno de ellos la "relación de aspectos críticos en sostenibilidad medioambiental y social, así como propuestas de acción” (Secretaría General de Turismo, 2007, p. 134).

\subsection{El Plan Nacional e Integral de Turismo 2012-2015 (Plan 1215)}

El Plan 1215 fue impulsado desde el Ministerio de Industria, Energía y Turismo y se aprobó en junio de 2012, con el gobierno del Partido Popular de Mariano Rajoy. En su elaboración se implicaron actores públicos y privados, aunque el nivel de participación en términos cuantitativos fue menor que en el Plan 2020. Es un documento estratégico que, pese a estar limitado por una cobertura temporal de cuatro años, a diferencia del Plan 2020, incorpora medidas e indicadores concretos de implementación y seguimiento. La extensión del documento es de 123 páginas, en las que las palabras clave sostenible, sostenibles o sostenibilidad aparecen 35 veces, y medioambiente, ambiente, medioambiental o ambiental se leen en 27 ocasiones.

El plan se define a sí mismo como nacional -destino y marca España-; integral -afecta a diferentes ámbitos: político, social, económico...-; estratégico y operativo; fundamentado en planes anteriores; coordinado, controlado y medible -incluye indicadores de seguimiento-; y transparente, mediante la comunicación pública del grado de avance del mismo. Su visión dice: "el Destino España se orienta a generar una diferenciación relevante para el consumidor, en la que todos los recursos culturales, naturales, empresariales y de servicio público se ponen al servicio del turista" (Secretaría de Estado de Turismo y Turespaña, 2012, p. 37). 
El Plan 1215 se compone de ocho apartados, esquematizados en la Tabla 6. Tras la presentación e introducción, se expone un diagnóstico DAFO (Debilidades, Amenazas, Fortalezas y Oportunidades), que enlaza con la visión y objetivos. A continuación, las medidas se agrupan en torno a los seis ejes del diagnóstico y constituyen el grueso del documento. Posteriormente se establece una priorización de medidas. Finalmente, se trata el seguimiento y control del plan, que se realizará mediante: el Consejo Español de Turismo, la Conferencia Sectorial y la Comisión Interministerial. Este apartado no deja de ser una declaración de intenciones, pues remite el diseño del seguimiento a un futuro Plan de Gestión y a la consiguiente habilitación de una Oficina de Seguimiento y Control.

Tabla 6

ESTRUCTURA DEL PLAN 1215

\begin{tabular}{|c|c|c|}
\hline \multirow{18}{*}{ 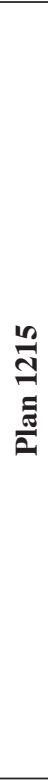 } & Presentación & Siglas y abreviaturas \\
\hline & \multirow{2}{*}{ Introducción } & Introducción al PNIT \\
\hline & & Estructura del PNIT \\
\hline & \multirow{2}{*}{ Diagnóstico } & Visión General \\
\hline & & Diagnóstico \\
\hline & \multirow{2}{*}{ Destino España: Visión y Objetivos } & Destino España: Visión \\
\hline & & Objetivos para el Destino España \\
\hline & \multirow{6}{*}{ Medidas } & Fuerza de la marca España \\
\hline & & Orientación al cliente \\
\hline & & Oferta y destinos \\
\hline & & Alineamiento de actores público-privado \\
\hline & & Conocimiento \\
\hline & & Talento y emprendeduría \\
\hline & \multirow{2}{*}{ Priorización de Medidas } & Metodología de priorización \\
\hline & & Evaluación de las medidas \\
\hline & \multirow{2}{*}{ Seguimiento y Control } & Instrumentos de coordinación \\
\hline & & Seguimiento y control \\
\hline & Anexo & Aportaciones al PNIT \\
\hline
\end{tabular}

Fuente: elaboración propia a partir del Plan 1215.

En la introducción, además de poner en valor el peso del turismo en clave económica, se afirma que "la sostenibilidad económica, social y medioambiental de nuestro modelo está en entredicho de cara al futuro (Secretaría de Estado de Turismo y Turespaña, 2012, p. 13)”. En el diagnóstico, sobre las cuestiones de carácter ambiental, se concibe como una oportunidad que "la demanda sensible a atributos relacionados con la sostenibilidad del medio ambiente está ganando mayor peso entre los turistas internacionales" (Secretaría de Estado de Turismo y Turespaña, 2012, p. 25). Respecto a las debilidades, entre los elementos que peor valoran los turistas que visitan España está el medio ambiente. Además, "el turista objetivo para el producto de sol y playa busca atributos fácilmente replicables por otros destinos, como el clima, las playas y el ambiente, lo que conduce a una compe- 
tencia basada en el precio" (Secretaría de Estado de Turismo y Turespaña, 2012, p. 29). También se habla de los problemas de sostenibilidad asociados a la estacionalidad de la oferta de sol y playa, así como el elevado impacto ambiental del sector turístico español.

Tras el diagnóstico, en el que persisten problemas ya expuestos en los planes anteriores, se propone la visión del destino España. Las características del destino y los objetivos para alcanzarlas, se recogen en la Tabla 7. Como se observa, pese a que una de las características que se visiona es ser "sostenible económica, social y medioambientalmente (...) haciendo un uso responsable de los recursos naturales" (Secretaría de Estado de Turismo y Turespaña, 2012, p. 37), la cuestión medioambiental no está contemplada entre los objetivos. La Tabla 8 lista las medidas que propone el plan, organizadas de acuerdo a los ejes del diagnóstico y resaltando aquellas que se comentan a continuación por su mayor o menor vinculación con la sostenibilidad medioambiental.

\section{Tabla 7}

\section{VISIÓN Y OBJETIVOS DEL PLAN 1215}

\begin{tabular}{|c|c|c|}
\hline \multirow{14}{*}{$\begin{array}{l}\text { Destino } \\
\text { España: } \\
\text { Visión y } \\
\text { Objetivos }\end{array}$} & \multirow{7}{*}{$\begin{array}{l}\text { Destino } \\
\text { España: } \\
\text { Visión }\end{array}$} & Líder con proyección internacional \\
\hline & & Sostenible económica, social y medioambientalmente \\
\hline & & Excelente en talento (innovación) \\
\hline & & Colaborativa entre sectores público y privado \\
\hline & & Eficiente en su modelo empresarial con Europa como marco de referencia \\
\hline & & Con destinos rentables \\
\hline & & Inmersa en la era digital \\
\hline & \multirow{7}{*}{$\begin{array}{l}\text { Objetivos } \\
\text { para el } \\
\text { Destino } \\
\text { España }\end{array}$} & Incrementar la actividad turística y su rentabilidad \\
\hline & & Generar empleo de calidad \\
\hline & & Impulsar la unidad de mercado \\
\hline & & Mejorar el posicionamiento internacional \\
\hline & & Mejorar la cohesión y notoriedad de la marca España \\
\hline & & Favorecer la corresponsabilidad público-privado \\
\hline & & Fomentar la desestacionalización \\
\hline
\end{tabular}

Fuente: elaboración propia a partir del Plan 1215.

La primera medida destacada -B3-, se orienta a favorecer la desestacionalización e incrementar el número de viajeros. También se quiere disminuir el impacto social y medioambiental que ocasionan los picos de demanda, tales como la contaminación acústica o la acumulación de $\mathrm{CO}_{2}$. No obstante, la previsión de formar un grupo de trabajo para desarrollar esta medida no contempla la participación del Ministerio de Agricultura, Alimentación y Medio Ambiente, sino que sólo explicita la implicación del Ministerio de Fomento, Hacienda y Administraciones Públicas, y el Ministerio de Industria, Energía y Turismo.

En el eje de destinos pueden subrayarse: la intención de implementar las Agendas 21 como instrumento de gestión de los municipios turísticos, que ayudaría a alcanzar el estatus de municipio sostenible, ya que "la preocupación de la sostenibilidad, que hace unos años podría considerarse como un adorno accesorio y prescindible en la estrategia de los destinos, es cada vez más un factor de compra o de rechazo por parte de los destinatarios"(Secretaría 
de Estado de Turismo y Turespaña, 2012, p. 70) -C3-; y la voluntad de poner en valor el patrimonio natural, entre otros, diseñando, en colaboración con la Secretaría de Estado de Medio Ambiente, productos de ecoturismo y de naturaleza -C8-. Lo más destacable del eje es el fomento del turismo sostenible con el medio ambiente -C9-, afirmando que "la sostenibilidad del turismo medioambiental debe contemplarse como una herramienta horizontal que puede aplicarse en los destinos y recursos turísticos"(Secretaría de Estado de Turismo y Turespaña, 2012, p. 82). Sin embargo, la argumentación de esta última medida se centra en la reducción de costes relacionada con una mayor eficiencia energética y en la necesidad de satisfacer a una demanda cada vez más sensible con el medioambiente. Esta medida propone mejorar el sistema de certificaciones, favorecer los vínculos entre las empresas turísticas y el mercado de compensación de emisiones de $\mathrm{CO}_{2}$ y sensibilizar a los turistas

\section{Tabla 8 \\ MEDIDAS DEL PLAN 1215}

\begin{tabular}{|c|c|c|}
\hline \multirow{28}{*}{ Medidas } & \multirow{3}{*}{$\begin{array}{l}\text { A) Fuerza de la } \\
\text { marca España }\end{array}$} & A1. Desarrollo coordinado de la marca España \\
\hline & & A2. Impulso al Plan Estratégico de Marketing \\
\hline & & A3. Representación permanente de los intereses turísticos españoles en la UE \\
\hline & \multirow{4}{*}{$\begin{array}{l}\text { B) Orientación al } \\
\text { cliente }\end{array}$} & B1. Lanzamiento del programa "Fidelización España" \\
\hline & & B2. Impulso a una campaña para estimular la demanda turística nacional \\
\hline & & B3. Modulación de tasas aeroportuarias \\
\hline & & B4. Optimización en la expedición de visados turísticos \\
\hline & \multirow{9}{*}{$\begin{array}{l}\text { C) Oferta y } \\
\text { destinos }\end{array}$} & C1. Apoyo a la reconversión de destinos maduros \\
\hline & & C2. Líneas de crédito para la renovación de infraestructuras turísticas \\
\hline & & C3. Apoyo a los Municipios Turísticos \\
\hline & & C4. Destinos inteligentes: innovación en la gestión de destinos \\
\hline & & C5. Redes de agencias de gestión de experiencias \\
\hline & & $\begin{array}{l}\text { C6. Homogeneización de la clasificación y categorización de establecimientos hoteleros, } \\
\text { rurales y campings }\end{array}$ \\
\hline & & C7. Evolución del Sistema de Calidad Turístico Español \\
\hline & & C8. Puesta en valor del patrimonio cultural, natural y enogastronómico \\
\hline & & C9. Fomento del turismo sostenible con el medio ambiente \\
\hline & \multirow{6}{*}{$\begin{array}{l}\text { D) Alineamiento } \\
\text { de actores } \\
\text { público-privado }\end{array}$} & D1. Análisis del impacto de toda propuesta normativa en el sector turístico \\
\hline & & D2. Impulso a la unidad de mercado \\
\hline & & D3. Modificación de la legislación que afecta al turismo \\
\hline & & D4. Entrada del sector privado en el ámbito de decisión y financiación de Turespaña \\
\hline & & D5. Apoyo a la internacionalización de las empresas turísticas españolas \\
\hline & & D6. Ventanilla única para empresas y emprendedores innovadores \\
\hline & \multirow{3}{*}{ E) Conocimiento } & E1. Desarrollo del catálogo de servicios de Turespaña \\
\hline & & E2. Reorganización y modernización de las Consejerías de Turismo de España en el Exterior \\
\hline & & E3. Reorientación de las estadísticas nacionales de turismo \\
\hline & \multirow{3}{*}{$\begin{array}{l}\text { F) Talento y } \\
\text { emprendeduría }\end{array}$} & F1. Líneas de crédito para jóvenes emprendedores en turismo \\
\hline & & F2. Programa de emprendedores innovadores turísticos \\
\hline & & F3. Adecuación de la oferta formativa y la investigación a la demanda empresarial \\
\hline
\end{tabular}

Fuente: elaboración propia a partir del Plan 1215. Nomenclatura propia para facilitar la explicación. 
En lo relativo a la coordinación entre la política turística y la medioambiental, no sólo se contemplan colaboraciones como la ya mencionada en la medida C8, sino que se alude a la transversalidad de la planificación turística en el eje de Alineamiento de actores público-privado (por ejemplo, las medidas D1 o D3). En concreto, se afirma que "este rasgo diferencial [la transversalidad] no se ha tenido en cuenta a la hora de legislar sobre aspectos que, sin ser de naturaleza propiamente turística, tienen de hecho importantes efectos en el desarrollo y la competitividad del sector" (Secretaría de Estado de Turismo y Turespaña, 2012, p. 86). En lo relativo a las competencias del Ministerio de Agricultura, Alimentación y Medio Ambiente, se habla de colaborar en la modificación de la Ley de Costas y la Ley de Aguas.

En general, este plan puede considerarse como un replanteamiento del enfoque y el tratamiento de la cuestión de sostenibilidad ambiental en relación al Plan 2020. Como ejemplo, puede mencionarse la medida $\mathrm{C} 2$, en tanto que modifica las anteriores líneas de crédito "para financiar infraestructuras que supusieran mejoras en el ámbito de la sostenibilidad ambiental, especialmente aquellas focalizadas en la eficiencia energética, ahorro de agua y energía" (Secretaría de Estado de Turismo y Turespaña, 2012, p. 68). Concretamente, "eliminando la limitación de inversiones financiables a aquellas que suponen mejoras tecnológicas o medioambientales" (Secretaría de Estado de Turismo \& Turespaña, 2012, p. 69), se desincentivan las actuaciones para mejorar el medioambiente.

Otro ejemplo es la priorización de medidas en función de una matriz que las agrupa en cuatro cuadrantes que ordenan, según el impacto y facilidad de implementación, la prioridad de actuación de mayor a menor: prioritario, estratégico, de mejora rápida y de mejora continua. Ninguna de las medidas comentadas se sitúa en el cuadrante prioritario y dos de ellas -la C8 y la C9- se ubican en el cuadrante peor valorado. Precisamente, la medida C9 Fomento del turismo sostenible con el medio ambiente, la más relevante según el tema de estudio, es la de menor prioridad del total de las veintiocho medidas del Plan 1215 (sólo un punto sobre cinco, tanto de impacto como de facilidad). Todo ello puede interpretarse, desde la perspectiva del discurso, como una disminución de la relevancia de las cuestiones ambientales en el Plan 1215 respecto a los anteriores además de su propio replanteamiento desde la propia perspectiva del papel de la política ambiental en la política turística para el caso específico del turismo de sol y playa.

\section{CONCLUSIONES}

Diversos autores han reconocido los problemas de sostenibilidad del turismo de sol y playa en España, en gran parte relacionados con las deficiencias en la planificación turística (Velasco González, 2008; López Sánchez y Pulido Fernández, 2013). En este artículo se han analizado los tres últimos planes turísticos de España: el Plan 2020, el Plan 0812 y el Plan 1215. Desde el enfoque del Análisis de Políticas Públicas, se ha puesto el énfasis en la relevancia de los argumentos políticos y los marcos interpretativos para comprender la acción pública. Los resultados constatan que a partir de dicho análisis pueden observarse similitudes, diferencias y replanteamientos del medio ambiente en la planificación turística que, ligadas a argumentos e ideas políticas, han podido condicionar la planificación y el éxito de los destinos. 
A grandes rasgos, los planes analizados comparten la necesidad de mejorar la coordinación del sector turístico con otros sectores. También incluyen referencias concretas al ámbito medioambiental, aunque tal y como se ha expuesto en el apartado 4, estos argumentos no siempre se reflejan en las medidas propuestas o en su posterior priorización y, en general, el medioambiente no recibe la atención que requiere, teniendo en cuenta que es un recurso clave para el turismo de sol y playa en España.

Por otro lado, la investigación discursiva y argumentativa a partir del contenido de planes turísticos permite identificar discontinuidades en la comprensión de lo relativo a la relación entre turismo y medio ambiente por parte de los poderes públicos, y por tanto, discontinuidades también en el reconocimiento y la priorización de problemas, así como en la propuesta de medidas para gestionar el turismo y lo que le concierne. Teniendo en cuenta que para las cuestiones medioambientales, entre otras, son imprescindibles estrategias políticas a más largo plazo que los ciclos legislativos, ya que, dicha discontinuidad supone una limitación en el gobierno y la acción pública que condiciona la sostenibilidad futura de algunos destinos.

La comparación entre los planes, que se sintetiza en la Tabla 9, apunta a la conclusión de que en el Plan 1215 la importancia de la cuestión medioambiental en su discurso y argumentación es menor que en el plan anterior. El Plan 2020 incluía ya el criterio de sostenibilidad en general en su visión estratégica e incluso dedicaba uno de sus ejes estructurales a la sostenibilidad del modelo. Los periodos de cobertura de los dos planes también difieren entre sí. La preocupación por la sostenibilidad del modelo reflejada en el Plan 2020 implicaba una planificación más allá del ciclo político, y contemplaba una visión a 14 años. Sin embargo, el último plan supone una vuelta a la planificación turística con metas de 4 años, ligadas a los cursos electorales. Las referencias a las palabras clave reafirman esta idea: sostenible, sostenibles o sostenibilidad superan el centenar de menciones en el Plan 2020, mientras que únicamente son 35 en el Plan 1215. Una disminución del $67,6 \%$, cifra muy similar a la de la reducción acaecida en relación a las palabras medioambiente, ambiente, medioambiental o ambiental (-64,5\%), pasando de 76 referencias a solo 27.

De estos planes, se desprende la necesidad de mejorar la coordinación entre las dos esferas políticas -turística y medioambiental-, incorporando de forma transversal el criterio de sostenibilidad ambiental y concediéndole más peso del que refleja la planificación turística estatal más reciente. Como se ha expuesto, aunque es necesaria la implicación de todos los actores que participan del turismo, es el sector público quien tiene capacidad para liderar y orientar la sostenibilidad del modelo turístico.

Finalmente, el análisis realizado pone de manifiesto la necesidad de profundizar en el estudio de las políticas turísticas y la acción pública del turismo desde la perspectiva del Análisis de las Políticas Públicas. De esta manera se podrá avanzar en la proposición de nuevos marcos analíticos que permitan dar respuesta a problemas persistentes desde el inicio de la actividad turística que no logran resolverse. La metodología utilizada permite analizar cuestiones clave en la planificación turística a partir de los documentos de política turística y comprender cuál es la perspectiva de los poderes públicos al respecto. Así, se pueden detectar deficiencias en la planificación con objeto de mejorar futuros instrumentos de intervención y de observar la evolución y continuidad, o no, de 
Tabla 9

LA SOSTENIBILIDAD AMBIENTAL EN EL PLAN 2020 Y EL PLAN 1215

\begin{tabular}{|c|c|c|}
\hline Indicador & Plan 2020 (+ Plan 0812) & Plan 1215 \\
\hline $\begin{array}{l}\text { Meta/visión } \\
\text { estratégica }\end{array}$ & $\begin{array}{l}\text { Incluye el criterio de sostenibilidad del } \\
\text { modelo aunque no se especifica la vertiente } \\
\text { medioambiental. Se relaciona con la } \\
\text { competitividad y el bienestar social. }\end{array}$ & $\begin{array}{l}\text { No incluye el criterio de sostenibilidad, } \\
\text { aunque menciona los recursos naturales } \\
\text { del destino España. Se relaciona con los } \\
\text { servicios para el turista como consumidor. }\end{array}$ \\
\hline $\begin{array}{l}\text { Periodo de } \\
\text { planificación }\end{array}$ & $\begin{array}{l}14 \text { años, permite incorporar objetivos a largo } \\
\text { plazo, como los relacionados con la sostenibilidad } \\
\text { y el medioambiente. }\end{array}$ & $\begin{array}{l}4 \text { años, no permite incorporar objetivos a } \\
\text { largo plazo como los relacionados con la } \\
\text { sostenibilidad y el medioambiente. }\end{array}$ \\
\hline $\begin{array}{l}\text { Ejes o líneas } \\
\text { estratégicas } \\
\text { principales }\end{array}$ & $\begin{array}{l}\text { Uno de los cinco ejes principales se dedica a } \\
\text { la sostenibilidad del modelo. En un segundo } \\
\text { nivel, este eje incluye un programa específico } \\
\text { relativo a medioambiente, y tres programas } \\
\text { que indirectamente incluyen cuestiones } \\
\text { medioambientales. }\end{array}$ & $\begin{array}{l}\text { La sostenibilidad económica, social } \\
\text { y medioambiental es una de las siete } \\
\text { características de la visión estratégica del } \\
\text { destino España. Sin embargo, no constituye } \\
\text { un apartado de este plan y ninguno de } \\
\text { los objetivos, que guían la propuesta de } \\
\text { medidas, tiene que ver con la sostenibilidad } \\
\text { medioambiental, sino que obedecen todos a } \\
\text { criterios económicos y de mercado. }\end{array}$ \\
\hline $\begin{array}{l}\text { Criterios de } \\
\text { priorización }\end{array}$ & No se detallan. & $\begin{array}{l}\text { Incluye una matriz que según el impacto y } \\
\text { la facilidad de implementación, ordena las } \\
\text { medidas de mayor a menor prioridad en } \\
\text { cuatro cuadrantes. Ninguna medida relativa } \\
\text { al medioambiente se sitúa en el cuadrante } \\
\text { prioritario. La medida de fomento del } \\
\text { turismo sostenible con el medio ambiente } \\
\text { se le atribuye la prioridad más baja de todo } \\
\text { el paquete de medidas que incluye este } \\
\text { plan. }\end{array}$ \\
\hline $\begin{array}{l}\text { Coordinación } \\
\text { explícita turismo- } \\
\text { medioambiente }\end{array}$ & $\begin{array}{l}\text {-"Participación de la administración turística en la } \\
\text { estrategia nacional de cambio climático, a través de } \\
\text { la Oficina Española de Cambio Climático" (p. 121). } \\
\text {-Incluye la línea de acción Grupos de trabajo de } \\
\text { la Comisión Interministerial. Expresamente, se } \\
\text { quiere adecuar la "normativa medioambiental } \\
\text { referida, entre otras cosas, a la gestión de residuos, } \\
\text { gestión del agua y gestión energética de hoteles y } \\
\text { otros establecimientos turísticos" (p. 130). } \\
\text {-En el programa Cultura cooperativa, se habla } \\
\text { explícitamente de colaboración interdepartamental } \\
\text { entre turismo y sostenibilidad medioambiental. } \\
\text { (p. 132). }\end{array}$ & $\begin{array}{l}\text {-La medida Puesta en valor del patrimonio } \\
\text { cultural, natural y enogastronómico, } \\
\text { incluye el diseño de productos en } \\
\text { colaboración con la Secretaría de Estado de } \\
\text { Medio ambiente (p. 80). } \\
\text {-Se propone la colaboración explícita del } \\
\text { Ministerio de Agricultura, Alimentación y } \\
\text { Medio Ambiente para la modificación de } \\
\text { la Ley de costas (p. 88) y la Ley de Aguas } \\
\text { (p. 91). }\end{array}$ \\
\hline \multirow{2}{*}{$\begin{array}{l}\text { Frecuencia } \\
\text { palabras clave }\left(\mathrm{N}^{0}\right. \\
\text { de veces / palabra) }\end{array}$} & 108/ Sostenible, Sostenibles o Sostenibilidad & 35/ Sostenible, Sostenibles o Sostenibilidad \\
\hline & $\begin{array}{l}\text { 76/ Medioambiente, Medioambiental, Ambiente o } \\
\text { Ambiental }\end{array}$ & $\begin{array}{l}\text { 27/ Medioambiente, Medioambiental, } \\
\text { Ambiente o Ambiental }\end{array}$ \\
\hline
\end{tabular}

Fuente: elaboración propia. 
ideas y conceptos estratégicos en las políticas turísticas. Desde esta perspectiva, es de interés llevar a cabo futuras investigaciones que consideren no sólo una comparación evolutiva más larga, sino también sincrónica entre distintos niveles de gobierno o entre diferentes destinos turísticos.

\section{BIBLIOGRAFÍA}

AEVAL (2010): Fundamentos de Evaluación de Políticas Públicas. Madrid, Ministerio de Política Territorial y Administración Pública, Agencia Estatal de Evaluación de Políticas Públicas y Calidad de los Servicios. Gobierno de España.

AMELUNG, B., NICHOLLS, S. y VINER, D. (2007): «Implications of Global Climate Change for Tourism Flows and Seasonality», Journal of Travel Research, ${ }^{\circ}$ 45, pp. 285-296.

ANTON CLAVÉ, S. (1992): «Medio ambiente y política turística. Medidas comunitarias y estrategias de competitividad del turismo español», Estudios Turísticos, n 116, pp. 5-25.

ANTON CLAVÉ, S. (2004): «De los procesos de diversificación y cualificación a los productos turísticos emergentes. Cambios y oportunidades en la dinámica reciente del turismo litoral», Papeles de Economía Española, n 102, pp. 316-333.

BEAS SECALL, L. (2009): Les polítiques turístiques en el marc de la reestructuració de les destinacions litorals. Avaluació dels Plans d'excelencia turística al litoral catalá. Tarragona, Universitat Rovira i Virgili.

BECKEN, S. y HAY, J. (2012): Climate Change and Tourism. From policy to practice. New York, Routledge.

BORRELL MERLIN, M.D. (2005): «Turismo, medioambiente y desarrollo sostenible en el Mediterráneo», Observatorio Medioambiental, no 8, pp. 305-330.

BORRELL MERLIN, M.D. (2007): «Las políticas de medioambiente en la UE y el litoral mediterráneo español», Observatorio Medioambiental, nº 10, pp. 325-337.

BRAMWELL, B. y LANE, B. (2014): «The 'critical turn' and its implications for sustainable tourism research», Journal of Sustainable Tourism, $\mathrm{n}^{\circ}$ 22, pp. 1-8.

BUCKELY, R. (2012): «Sustainable tourism: research and reality», Annals of Tourism Research, $\mathrm{n}^{\mathrm{o}} 2$, pp. 528-546.

BUHALIS, D. (2000): «Marketing the competitive destination of the future», Tourism Management, $\mathrm{n}^{\mathrm{o}} 21$, pp. 97-116.

BUTLER, R. (1980): «The concept of a tourist area cycle of evolution: Implications for management of resources», Canadian Geographer, n 24, pp. 5-12.

COMISIÓN EUROPEA (2010): Europa, primer destino turístico del mundo: un nuevo marco político para el turismo europeo. Bruselas, Comunicación de la Comisión al Parlamento Europeo, al Consejo, al Comié Económico y Social Europeo y al Comité de las Regiones.

CUADRADO ROURA, J.R. y LÓPEZ MORALES, J.M. (2011): «El turismo: un sector clave en la economía española», Papeles de Economía Española, nº 128, pp. 2-20.

DE FREITAS, C.R., SCOTT, D. y MCBOYLE, G. (2008): «A second generation climate index for tourism (CIT): specification and verification», International Journal of Biometeorology, $\mathrm{n}^{\circ}$ 52, pp. 399-407. 
DREDGE, D. y JAMAL, T. (2015): «Progress in tourism planning and policy: A poststructural perspective on knowledge production», Tourism Management, $\mathrm{n}^{\circ}$ 51, pp. 285-297.

EIJGELAAR, E. y PEETERS, P. (2014): «The Global Footprint of Tourism», en The Wiley-Blackwell Companion to Tourism. Chichester, John Wiley \& Sons, pp. 454-465. ELLIOTT, J. (1997): Tourism: Politics and public sector management. London, Routledge. ENSERINK, B., KOPPENJAN, J. y MAYER, I (2013): «A Policy Sciences View on Policy Analysis», en Public Policy Analysis: New Developments. New York, Springer, pp. 11-40.

EUROSTAT (2014): Database of Number of establishments, bedrooms and bed-places by coastal and non-coastal area (from 2012 onwards). Disponible en http://appsso. eurostat.ec.europa.eu/nui/submitViewTableAction.do

EXCELTUR (2016): «Valoración turística empresarial de 2015 y perspectivas para 2006», en Informe perspectivas turíticas, $\mathrm{n}^{\circ} 55$.

FARINÓS, J. (2008): «Gobernanza territorial para el desarrollo sostenible: estado de la cuestión y agenda», Boletín de la Asociación de Geógrafos Españoles, $\mathrm{n}^{\circ} 46$ - 2008, pp. 11-32.

FARSARI, I., BUTLER, R.W., y SZIVAS, E. (2011): «Complexity in tourism policies: a cognitive mapping approach», Annals of Tourism Research, $\mathrm{n}^{\circ} 38$, pp. 1110-1134.

FERNÁNDEZ TABALES, A., BASCARÁN ESTÉVEZ, M.V., MERCADO ALONSO, I. y VILLAR LAMA, A. (2014): «La gobernanza territorial como nuevo enfoque para la gestión sostenible en destinos turísticos: planteamientos teóricos, frustraciones prácticas y posibilidades de futuro», en $V$ Congreso Internacional en Gobierno Administración y Políticas Públicas. Madrid, GIGAPP-IUIOG, Instituto Nacional de Administración Pública.

FISHER, F. y FORESTER, J. (1993): The Argumentative Turn in Policy Analysis and Planning. Durham, Duke University Press.

FISHER, F. y GOTTWEIS, H. (2012): The argumentative turn revised: Public policy as communicative practice. Durham, Duke University Press.

FISHER, F., MILLER, G. y SIDNEY, M. (2007): Handbook of Public Policy Analysis: Theory, Politics, and Methods. Boca Raton, FL, Taylor \& Francis.

GÓMEZ MARTÍN, B. (2004): «An evaluation of the tourist potential of the climate in Catalonia (Spain): a regional study», Geografiska Annaler, n 3, pp. 249-264.

GUTHRIE, G. (2010): Basic Research Methods: An Entry to Social Science Research. New Delhi, Sage Publications.

HAJER, M.A. (1993): «Discourse coalitions and the institutionalization of practice: the case of acid rain in Great Britain», en The Argumentative Turn in Policy Analysis and Planning. Durham, Duke University Press, pp. 43-76.

HALL, C.M. (1994): Tourism and politics: policy, power and place. Chichester, Wiley. HARguindÉGUY, J.B. (2015): Análisis de Políticas Públicas. Madrid, Tecnos.

INE (2012): Cuenta Satélite del Turismo en España. Instituto Nacional de Estadística.

INE (2015): Encuesta de Ocupación de Alojamientos Turísticos (Establecimientos hoteleros). Insitutot Nacional de Estadística. 
IVARS, J.A. (2001): Planificación y gestión del desarrollo turístico sostenible: propuesta para la creación de un sistema de indicadores. Documento de Trabajo $\mathrm{n}^{\circ} 1$. Instituto Universitario de Geografía. Universidad de Alicante.

JENKINS, J.M., HALL, C.M. y MKNO, M. (2014): «Tourism and Public Policy: Contemporary Debates and Future Directions», en The Wiley Blackwell Companion to Tourism. Chichester, John Wiley \& Sons, pp. 542-555.

JIMÉNEZ HERRERO, L.M. (2007): «Hacia la sostenibilidad turística en españa», Estudios Turisticos, $\mathrm{n}^{\circ}$ 172-173, pp. 73-79.

KNOWLES, T. y CURTIS, S. (1999). «The market viability of European mass tourist destinations: A post-stagnation life cycle analysis», International Journal of Tourism Research, $\mathrm{n}^{\circ} 1$, pp. 87-96.

KOHLBACHER, F. (2006): «The Use of Qualitative Content Analysis in Case Study Research», Forum Qualitative Social Research, n 7, pp. 3-13.

LEÓN, C.J. (2004): «Desarrollo sostenible, medio ambiente y preferencias en el turismo», Papeles de Economía Española, no 102, pp. 287-297.

LESLIE, D. (2012): Responsible Tourism: Concepts, Theory and Practice. Oxfordshire, Cabi.

LÓPEZ SÁNCHEZ, Y. y PULIDO FERNÁNDEZ, J.I. (2013): «La sostenibilidad en la política turística española ¿avances o retrocesos?», Papers de Turisme, nº 53, pp. 44-68.

MAXIM, C. (2016): «Sustainable tourism implementation in urban areas: a case study of London», Journal of SustainableTourism, n 24, pp. 971-989.

MAYRING, P. (2000): «Qualitative Content Analysis», Forum Qualitative Social Research, $\mathrm{n}^{\circ} 1$, Art. 20.

MINISTERIO DE LA PRESIDENCIA (2007): Estrategia Española de Desarrollo Sostenible. Madrid, Gobierno de España.

MONFORT MIR, V. (2000): «La política turística: una aproximación», Cuadernos de Turismo, $\mathrm{n}^{\circ}$ 6, pp. 7-27.

OMT (2007): De Davos a Bali: la contribución del turismo al reto del cambio climático. Organización Mundial del Turismo.

OMT (2015): Panorama OMT del Turismo Interacional. Organización Mundial del Turismo.

ONU (1987): Nuestro futuro común. Informe de la Comisión Mundial sobre el Medio Ambiente y el Desarrollo. Organización de las Naciones Unidas.

PAGE, S. y CONNELL, J. (2006): Tourism: A Modern Synthesis. London, Thomson.

PARSONS, W. (1995): Public policy: an introduction to the theory and practice of policy analysis. Cheltenham, Edward Elgar Publishing.

PÉREZ, P. (2012): «El ciclo de vida de un área turistica : su aplicacion a la Costa del Sol española y su medio ambiente», Observatorio Medioambiental, no 15, pp. 21-34.

PRIDEAUX, B. (2013): «Climate change and peak oil - two large-scale disruptions likely to adversely affect long-term tourism growth in the Asia Pacific», Journal of Destination Marketing \& Management, $\mathrm{n}^{\mathrm{o}} 2$, pp. 132-136.

PROVAN, K.G. y KENIS, P. (2007): «Modes of network governance: structure, management, and effectiveness», Journal of Public Administration Research and Theory, $\mathrm{n}^{\circ}$ 18, pp. 229-252. 
PULIDO FERNÁNDEZ, J.I. (2004): «El medio ambiente en la política turística española», Quaderns de Política Económica, n 7 , pp. 93-114.

PULIDO FERNÁNDEZ, J.I. (2011): «La sostenibilidad del modelo turístico español en un escenario de cambio global», Papeles de Economía Española, no 128, pp. 38-52.

PULIDO FERNÁNDEZ, J.I. y LÓPEZ SÁNCHEZ, Y. (2013): «Propuesta de contenidos para una política turística sostenible en España», Pasos. Revista de Turismo y Patrimonio cultural, $\mathrm{n}^{\mathrm{o}} 11$, pp. 525-546.

PULIDO FERNÁNDEZ, J.I. y PULIDO FERNÁNDEZ, M.C. (2015): «¿Sigue vigente el paradigma del turismo sostenible? Reflexiones a la luz de la literatura reciente», Pasos. Revista de Turismo y Patrimonio cultural, $\mathrm{n}^{\circ}$ 13, 1315-1335.

QUINTILIANI, F. (2009): «International tourism in the coastal regions of five Mediterranean countries», Tourism Analysis, $\mathrm{n}^{\circ} 14,353-373$.

SALADIÉ, O. y OLIVERAS, J. (2010): Desenvolupament sostenible. Tarragona, Universitat Rovira i Virgili.

SANTOS PAVÓN, E.L. y FERNÁNDEZ TABALES, A. (2010): «El litoral turístico español en la encrucijada: entre la renovación y el continuismo», Cuadernos de Economía, $\mathrm{n}^{\mathrm{o}} 25$, pp. 185-206.

SCOTT, D. (2014): «Climate-Change Implications for Tourism», en The Wiley Blackwell Companion to Tourism. Chichester, John Wiley \& Sons, pp. 466-478.

SCOTT, D. y MCBOYLE, G. (2001): «Using a "tourism climate index" to examine the implications of climate change for climate as a tourism resource» en First International Workshop on Climate, Tourism and Recreation. Halkidiki, International Society of Biometeorology, pp. 69-88.

SECRETARÍA DE ESTADO DE TURISMO y TURESPAÑA (2012): Plan Nacional e Integral de Turismo 2012-2015. Madrid, Ministerio de Industria, Energía y Turismo, Gobierno de España.

SECRETARIA GENERAL DE TURISMO (1990): «Libro Blanco del Turismo Español», Estudios Turísticos, ${ }^{\circ}$ 108, pp.3-60.

SECRETARÍA GENERAL DE TURISMO (2007): Plan del Turismo Español Horizonte 2020. Madrid, Ministerio de Industria, Turismo y Comercio, Gobierno de España.

SUBIRATS, J. (1989): Análisis de políticas públicas y eficacia de la Administración. Madrid, INAP.

SUBIRATS, J., KNOEPFEL, P., LARRUE, C. y VARONNE, F. (2008): Análisis y gestión de políticas públicas. Barcelona, Ariel.

TORRES-DELGADO, A. (2010): «Certificaciones ambientales, productos innovadores y redes de cooperación: iniciativas de turismo sostenible en nuevos destinos de Cataluña», Revista de Análisis Turístico, n 10, pp. 1-8.

TORRES-DELGADO, A. y LÓPEZ PALOMEQUE, F. (2012): «The growth and spread of the concept of sustainable tourism: The contribution of institutional initiatives to tourism policy», Tourism Management Perspectives, $\mathrm{n}^{\circ}$ 4, pp. 1-10.

TURESPAÑA (2014): Entradas de turistas según Comunidad autónoma de destino principal. Año 2014. Movimientos Turísticos en Fronteras (Frontur), Ministerio de Industria, Energía y Turismo, Gobierno de España. 
TURESPAÑA (2015): Job Statistics. Disponible en: http://estadisticas.tourspain.es/en-en/ estadisticas/otrasestadisticas/empleoturistico/paginas/default.aspx.

VELASCO GONZÁLEZ, M. (2004): La política turística. Gobierno y Administración Turística en España (1952-2004). Valencia, Tirant lo Blanch.

VELASCO GONZÁLEZ, M. (2008): «Evolución de los problemas del turismo español. La Administración General del Estado como analista y los planes públicos como indicadores (1952-2006)», Papers de Turisme, n 43-44, pp. 7-31.

VELASCO GONZÁLEZ, M. (2010): «La incorporación de ideas en las políticas públicas. El concepto de sostenibilidad en la política turística», Revista de Análisis Turístico, $\mathrm{n}^{\circ} 10$, pp. 35-44.

VELASCO GONZÁLEZ, M. (2011): «La política turística. Una arena de acción autónoma», Cuadernos de Turismo, no 27, pp. 953-969.

VERA REBOLLO, J.F. e IVARS, J. (2009): «Spread of low-cost carriers: tourism and regional policy effects in Spain», Regional Studies, n 43, pp. 559-570.

VERA REBOLLO, J.F. y BAÑOS CASTIÑEIRA, C.J. (2004): «Turismo, territorio y medio ambiente. La necesaria sostenibilidad», Papeles de Economía Española, $\mathrm{n}^{\circ}$ 102, pp. 271-286.

VERA REBOLLO, J.F. y RODRÍGUEZ, I. (2012): Renovación y reestructuración de destinos turísticos en áreas costeras. Marco de análisis, procesos, instrumentos y realidades. Valencia, Universidad de Valencia.

WEBER, R.P. (1990): Basic Content Analysis. Newbury Park, California, Sage Publications. 